\title{
AC 2012-4770: BREAKING NEW GROUND FROM THE STEM-UP
}

Dr. Gary Cruz, Great Minds in STEM

Lupe Munoz Alvarado, Great Minds in STEM

(C)American Society for Engineering Education, 2012 


\title{
Breaking New Ground from the STEM-Up ${ }^{\mathrm{TM}}$
}

\author{
Affiliation: Great Minds in STEM ${ }^{\mathrm{TM}}$
}

\begin{abstract}
Great Minds in STEM ${ }^{\mathrm{TM}}$ (GMiS) is a national organization focused on accelerating the awareness of science, technology, engineering and math (STEM) among the nation's most underserved and underrepresented communities. As GMiS maintains a hand on the pulse of the national STEM crisis, it has created a STEM Movement within the Boyle Heights community of Los Angeles to ameliorate the flailing numbers of Latinos prepared to enter into and pursue STEM careers. In an effort to build STEM capacity, GMiS developed the STEM-Up ${ }^{\mathrm{TM}}$ Initiative. This Initiative is a community-building, culturally responsive mechanism intended to effectively create sustained affinity toward STEM. The ultimate goal of STEM-Up ${ }^{\mathrm{TM}}$ is to transform the attitudes, perceptions and behaviors of students, teachers, administrators and parents regarding the pursuit of math and science as a viable career pathway.
\end{abstract}

Now, in its fourth-year of a five-year pilot performance-based contract from the U.S. Department of Defense, the STEM-Up ${ }^{\mathrm{TM}}$ Initiative has helped create a transformative network and developed a menu of opportunities that has successfully engaged $20 \mathrm{~K}-12$ schools and hosted over 18,000 students through direct classroom and out-of-school activities. STEM-Up ${ }^{\mathrm{TM}}$ has developed school agendas, hands-on classroom activities for $4^{\text {th }}-6^{\text {th }}$ grade students, the Viva Technology ${ }^{\mathrm{TM}}$ Program for middle school and high school students, parent workshops, an educators' institute, and teacher ambassadors.

\section{Introduction}

At the core of the New Economy is science, technology, engineering and math (STEM), an artifact that must increasingly be leveraged to maximize earning potential and learning experiences. The economic well-being of the United States hinges on its capacity for technological innovation, which depends on a competitive supply of high-skilled, technical workers to innovate, and attract and retain new high-tech industries. According to the U.S. Department of Commerce (Langdon, McKittrick, Beede, Knah, \& Doms, 2011) ${ }^{1}$ over the past 10 years, STEM jobs grew three times faster then non-STEM jobs. Between 2008 and 2018, STEM jobs are projected to grow by 17 percent compared to 9.8 percent growth for non-STEM jobs. The concern for the U.S. is being able to supply a well-educated technical workforce.

Education provides individuals with the $21^{\text {st }}$ Century knowledge, skills and competencies that are needed to fully participate in the New Economy. By 2016, four out of every 10 new jobs (40 percent) will require some advanced education or training (Dohm \& Shniper, 2007) ${ }^{2}$. Fifteen of 
the 30 fastest-growing fields (50 percent) will require a minimum of a bachelor's degree (Bureau of Labor Statistics, 2007) ${ }^{3}$.

In 2009, President Obama, set a national goal that by 2020, America would once again have the highest proportion of college graduates in the world. This meant raising the population proportion of college graduates with a two-year or four-year degree, from 41 percent to 60 percent (U.S. Department of Education, 2010) ${ }^{4}$. The translation to real numbers means that the U.S. needs to produce an additional 13.4 million associate's and bachelor's degrees holders by 2020, to reach at least 51 percent (Santiago \& Callan, 2010) ${ }^{5}$. For Latinos, degree attainment needs to increase by 3.3 million to an annual total of 5.5 million and would represent almost 25 percent of all additional degrees earned. (Santiago \& Callan, 2010) ${ }^{6}$.

Yet, for the United States to retain its global leadership in science and technology, then over the next decade it must not only just produce more college graduates, the country must produce 1 million more STEM professionals over its current rate. That is, the U.S. must increase its productions of STEM professionals by an additional 34 percent, each year, for the next ten years (President's Council of Advisors on Science and Technology, 2012) ${ }^{7}$.

California, the world's eighth largest economy (Milken Institute, 2010) ${ }^{8}$, currently excels at producing the entrepreneurs and capital so important to converting research into new business products and service. In fact, California is second in the nation in retaining its native-born highskilled workers. In 2009, California's high tech employment was 50 percent higher than the national average. These high-tech industries accounted for 1.3 million (9.3 percent) of the state's employment and more than 16 percent of the state's wages (Shen, Wong \& DeVol, 2011) ${ }^{9}$. However, the state now only produces 11 percent of the nation's science and engineering degrees (U.S. Department of Education, 2011) ${ }^{10}$, though it consumed 14.8 percent of the nation's engineering workforce in 2008 (Alliance for Science \& Technology Research in America, 2010) ${ }^{11}$. The need for a STEM-educated nation is imminent and comes at a time where states like California are in an economic crisis with constant increases in cuts to education.

Taking into account these national and local circumstances, Great Minds in STEM ${ }^{\mathrm{TM}}$ (GMiS), a national, 501c3 organization, has created a STEM Movement within the Boyle Heights community of East Los Angeles, California, to ameliorate the flailing numbers of Hispanics prepared to enter into and pursue STEM careers. Great Minds in STEM ${ }^{\mathrm{TM}}$ is supporting the expanded STEM development and preparation of the 92,000 Boyle Heights residents to be ready to fill the current and future local and national STEM occupations. Boyle Heights is engaged in STEM, as a catalyst for boosting student, educator and community interest, achievement and motivation to pursue STEM curricular tracks and teaching methods via both formal and informal learning opportunities.

This paper presents STEM-Up ${ }^{\mathrm{TM}}$ to the engineering community as a comprehensive best-practice that makes math and science a common vernacular within an underrepresented community. This paper is not a qualitative or quantitative study in the traditional sense of formal research. Rather, this paper highlights aspects of STEM-Up ${ }^{T M}$ as an informal science initiative that has created a menu of opportunities - i.e. a value chain - to broadly engage an entire community in creating a sustained network for an affinity toward science, technology, engineering and math. 


\section{Literature Review}

In the last several decades, the U.S. has shifted from a skill-based economy to a knowledgebased economy that requires technically skilled workers. This shift, combined with factors that include increased innovation and technological competition from abroad, a retiring baby boomer population, a decline of people entering the workforce, and a significant population shift toward an increasing growth in the Latino population, which has historically struggled to close the academic achievement gap, places a tremendous burden on the U.S. to remain a global leader in STEM. The national capacity to innovate in the New Economy requires broader participation of underrepresented communities, especially Latinos, which make up an increasingly large portion of the national population.

Several national reports have analyzed the underrepresented minority participation in science and engineering in the context of keeping America innovative and competitive (National Research Council, 2007, 2009, 2011) ${ }^{12,13,14}$. In 2007, Rising Above the Gathering Storm, the National Academy of Sciences sounded an alarm in response to statistical data that show a "troubling decline" in the number of U.S. citizens who are training to become scientists and engineers at a time when the number of jobs requiring technical and scientific skills is growing at more than four times the rate of the U.S. labor force. The National Science Board (2010) ${ }^{15}$ pointed out that the abilities and education of too many young people in the country are underdeveloped or unsupported. The shrinking pipeline producing the next generation STEM workforce clearly threatens the country's future preparedness in technology innovation, energy alternatives, resource development, national security, and education.

While underrepresented populations aspire to major in STEM disciplines, their undergraduate completion rates are significantly lower than White or Asian Americans students (National Research Council, 2011) ${ }^{16}$. This is especially alarming for Hispanics for which the percentage of the 24-year-old population having earned a first degree in natural sciences or engineering is only 2.2 percent, the lowest among all underrepresented minority groups including African Americans, Native Americans and Alaska Natives. Furthermore, it has also been noted that data from the 1990s revealed a similar picture. Consequently, while many efforts have been aimed at addressing the issue of minority underrepresentation in STEM in the last two decades, progress has been much slower than expected (National Research Council, 2010) ${ }^{17}$. This indicates that innovative, rapidly deployable solutions are needed to produce more efficient and timely results.

In the ten-year period from 1998 to 2008, the percent growth in engineering bachelor degrees awarded to U.S. citizens and permanent residents was 16.8 percent; among Hispanics the growth was 26.9 percent (National Science Foundation, 2011) ${ }^{18}$. Despite this growth, according to the National Science Foundation, in fall 2008, only 38 percent of 4-year, first-year Hispanic students indicated intend to pursue a science or engineering degree (National Science Foundation, 2011) 19. The Engineering Workforce Commission reported that Hispanics composed 9.5 percent of the 443,000 students enrolled in an undergraduate engineering program, in fall 2008 (National Science Foundation, 2011) ${ }^{20}$. Finally, in 2008, of the 65,715 engineering bachelor degrees, only 8 percent were awarded to Hispanics (National Science Foundation, 2011) ${ }^{21}$. If the United States wants to remain globally competitive, then it must increase its efforts to recruit, retain, and 
graduate more Hispanics with technical degrees in science, technology, engineering and mathematics. (de los Santos, Keller, Nettles, Payan, \& Magallan, 2006) ${ }^{22}$.

Given population trends, the supply of the future workforce will come from a young, Latino populace. As indicated by President Obama (U.S. Department of Education, 2011) ${ }^{23}$, "To...secure prosperity for all Americans, we must out-innovate, out-educate, and out-build the rest of the world. The Latino community is integral to that plan to win the future.” (p. 7) As projections indicate that Latinos will account for 60 percent of the Nation's population growth between 2005 and 2050, their success in education and in the labor market is of critical importance to maintaining a competitive American economy.

In 2010, there were 17.1 million Latino youth (ages 17 and younger), which constituted more than 23 percent of this age group overall. In the public PK-12 system, Latinos number nearly 22 percent, of all PK-12 students (U.S. Department of Education, 2011) ${ }^{24}$. Data from the Pew Hispanic Center (2010) ${ }^{25}$ continues to present a lagging portrait of the educational attainment of Latinos. Less than half of Latino youths are enrolled in early education, half of the population earns a high school diploma on time, and half are likely to be ready for college. In 2010, the preschool enrollment rate of Latino 3 and 4-year olds was 39.6 percent, compared to the 50 percent, 52 percent and 54 percent enrollment rates of Whites, Blacks and Asians, respectively. Regarding educational attainment, 37.7 percent of Latinos failed to at least graduate from high school, and 13.1 percent had attained a bachelor's degree, compared to 31.4 percent of Whites. The overall college enrollment rate of persons 18 to 24-years old was 31.1 percent for Hispanics; this was less than the total U.S. enrollment rate of 42.9 percent.

While formal, institutionalized practices are important to attract and retain underrepresented students in STEM, more needs to be known about the mechanisms that informal avenues of exposure provide to contribute to knowledge and retention in STEM. The National Science Foundation (NSF), National Institutes of Health (NIH), and other organizations have all provided funding in order to broaden participation in STEM by underrepresented ethnic/racial groups (Zhe, et al., 201026; Stolle-McAllister, Domingo, \& Carrillo, 2010 27). These programs have significantly built confidence and self-efficacy for their participants (Chacon \& Soto-Johnson, $2003^{28}$; Russell, Hancock, \& McCullough, 2007 ${ }^{29}$; Zhe, et al., 2010 ${ }^{30}$ ). Nevertheless, there continues to remain a scarcity of women and minorities pursuing STEM careers.

For Latinos the challenge for STEM persistence is great. Latino students are the most likely to drop out of high school, among the least likely to have access to qualified math and science teachers, more likely to confront economic and language barriers, often face student-to-counselor ratios that are under par, and have inadequate early science and math education. Among those Latino students, who do enroll in college, they often find STEM courses too demanding when coupled with financial and family obligations that encourage students to stay close to home, and face cultural traditions that perpetuate gender roles, especially for Latinas. These challenges present barriers that deter them as potential STEM professionals (NACME, 2008) ${ }^{31}$. To improve the STEM education for Latinos, the focus needs to be not only on preparation but also on inspiration. 
About Great Minds in STEM ${ }^{\mathrm{TM}}$

Great Minds in STEM ${ }^{\mathrm{TM}}$ is a 501(c)3 non-profit offering a series of targeted K-20 educational programs promoting college readiness, awareness, resources and access to STEM careers among underrepresented students. GMiS' vision is to be a national leader in keeping America technologically strong by promoting STEM careers, especially in underserved communities. GMiS seeks to motivate and empower students, parents, and teachers with the knowledge, skills and resources to pursue educational pathways that will lead to a technical career in the STEM workforce. With support from a substantial core of STEM-based supporters, GMiS continues its history of creating a national STEM awareness campaign and supplementing the academic and career development of Hispanic students and professionals. To date, achievements include the awarding of over \$1.3 M in STEM college scholarships to over 750 recipients, the development of the rapidly expanding bilingual hands-on K-12 Viva Technology ${ }^{\mathrm{TM}}$ Program, the hosting of the widely recognized HENAAC College Bowl ${ }^{\mathrm{TM}}$, and the comprehensive community partnership STEM-Up ${ }^{\mathrm{TM}}$ Initiative. These combined efforts demonstrate a unique and embedded commitment to continue the push for equitable representation of a STEM workforce, reflective of the ethnic/racial and gender diversity of the U.S. population.

The STEM-Up ${ }^{\mathrm{TM}}$ Initiative

In an effort to build STEM capacity, Great Minds in STEM ${ }^{\mathrm{TM}}$ developed the STEM-Up ${ }^{\mathrm{TM}}$ Initiative. Community engagement around STEM served as the change strategy to boost interest and achievement. Through a comprehensive and integrated approach, STEM-Up ${ }^{\mathrm{TM}}$ engages students, parents, teachers, and community-based organizations in creating a demand for highquality STEM awareness education. As a community-building, culturally responsive initiative, STEM-Up ${ }^{\mathrm{TM}}$ sought to effectively create sustained affinity toward STEM. The Initiative was to help catalyze, complement and enhance school-based efforts to build capacity in STEM resources. The ultimate goal of STEM-Up ${ }^{\mathrm{TM}}$ is to transform the attitudes, perceptions and behaviors of students, teachers, administrators and parents regarding the pursuit of math and science as a viable career pathway.

STEM-Up ${ }^{\mathrm{TM}}$ evolved from a high-level challenge posed by the U.S. Department of Defense, in October 2006, by then-Principal Deputy Undersecretary of Defense Michael Dominguez. He contended that the Nation's disjointed approach to STEM education and workforce development allows disproportionate numbers of under-represented minority students to fall between the cracks. Secretary Dominguez called for the establishment of an interconnected value-chain of learning opportunities that nurtures STEM talent in our fastest-growing populations as they move up the ladder from pre-school to college. Traditionally, the institutions that are engaged along the way - schools, colleges, companies, museums, clubs, competitions, and other community-based organizations - focus on their particular link rather than the chain as a whole.

Therein, GMiS secured a five-year performance-based contract from the U.S. Department of Defense, administered by the U.S. Army Corps of Engineers, Los Angeles District Office, to create STEM-Up $^{\mathrm{TM}}$. Piloted in Boyle Heights, a community in Los Angeles, this first-of-its-kind initiative is providing an innovative solution to the projected shortage of the Nation's STEM workforce. This Initiative, as an action strategy, materialized from a set of design principles, 
grounded in a theory of change. This theory suggests that a catalyst for boosting student interest and achievement around STEM can be created through community engagement. By implementing this catalyst through a chain of values, STEM-Up ${ }^{\mathrm{TM}}$ demonstrates that a broad, comprehensive and integrated effort to engage an entire community of 92,000 residents can complement and enhance school-based STEM education strategies. The design principles developed to underpin the theory of change and serve as a practical roadmap for transformation is known as AIMS - Awareness, Inspiration, Motivation, and Skills.

STEM-Up ${ }^{\mathrm{TM}}$ is not based on traditional school reform strategies, an approach that focuses on the individual gains in student achievement through such measures as curriculum, standardized testing, teacher skills, technology access, and school organization. Rather, STEM-Up ${ }^{\mathrm{TM}}$ seeks to leverage the whole community, and drive change in the mindset of the community to create a sustained college-going culture well beyond the Initiative. The goal of the Initiative is simple to engage a low-income, underserved community comprised of over 92,000 residents with a school-age population of 18,000 students, in building STEM capacity through transformative change. As a community engagement, empowerment, and self-efficacy strategy, STEM-Up ${ }^{\mathrm{TM}}$ intends to indirectly impact a long-term return on investment on traditional academic performance measures. Such a large-scale undertaking is a unique approach to STEM education awareness. To accomplish this undertaking, STEM-Up ${ }^{\mathrm{TM}}$ seeks to drives transformative change by leveraging the existing cultural richness of the community toward STEM.

In its design, STEM-Up ${ }^{\mathrm{TM}}$ relies on the parents and teachers as STEM Ambassadors, who are informed with the tools and resources to change the apprehensions and negativities associated with math and science. STEM-Up ${ }^{\mathrm{TM}}$ values parents and teachers as transformative institutional agents. Empowering them through training and education, that acknowledges the importance of their cultural reference within the vernacular of STEM, parents and teachers become more critical in creating transformative change in their community.

\section{Objectives}

The measured achievements of STEM-Up ${ }^{\mathrm{TM}}$ are to assist the schools to hone in on community resources to create a sustained college-going culture well beyond the initiative. The STEM$\mathrm{Up}^{\mathrm{TM}}$ model is a comprehensive program of interrelated links (activities) that are separate but connected along a chain of values. This strategy engages students, parents, teachers, and community-based organizations around hands-on activities, role models, and career opportunities in STEM. By closing gaps in AIMS, STEM-Up ${ }^{\mathrm{TM}}$ seeks a long-term investment in student knowledge of the pathway to college and STEM careers. These AIMS principles are woven into seven key performance objectives to meet immediate, intermediate and long-term outcomes (Table 1).

Table 1. STEM-Up ${ }^{\mathrm{TM}}$ Objectives

STEM-Up ${ }^{\mathrm{TM}}$ Objectives

Objective 1: Increase community awareness of the value and importance of STEM

Objective 2: Motivate students and families to prepare themselves for STEM careers 
Objective 3: Build long-term community support for expanding STEM capacity

Objective 4: Increase the STEM content knowledge of K-12 STEM teachers and administrators

Objective 5: Expand career opportunities in STEM fields

Objective 6: Raise the achievement of students in STEM disciplines.

Objective 7: Increase the number of students entering and being accepted into higher education.

STEM-Up ${ }^{\text {TM }}$ Timeline

\section{Base Year}

2008-09 laid the foundation for the STEM-Up ${ }^{\mathrm{TM}}$ Initiative. GMiS secured community trust, branded STEM-Up ${ }^{\mathrm{TM}}$, and framed an action agenda. The Initiative sought to develop a credible and solid conceptual underpinning to be established as a scalable model rather than a one-of-akind initiative. Strong branding and community trust was essential to strike a positive chord within the target community, especially its youth. GMiS conducted a comprehensive inventory of STEM learning opportunities in the Boyle Heights Community, developed a socio-economic profile of the community, and reviewed the baseline evaluation data of all schools. GMiS piloted bilingual parent workshops, Viva Technology ${ }^{\mathrm{TM}}$, role models at school events, and a STEMthemed student planner. In addition, GMiS initiated STEM professional development for teachers in collaboration with California State University, Los Angeles, College of Engineering, Computer Science and Technology.

\section{Option Year 1}

2009-10 marked a significant ramp-up of learning opportunities for students, parents and teachers in all schools. The program followed three operational goals: 1) To increase engagement of all key stakeholders through a rich menu of STEM-opportunities for students, parents, teachers and community members; 2) to expand the base of community support through one-onone relationships with key school administrators and collaboration with recognized local leaders and community based organizations; and 3) to begin measuring the impact of STEM-Up ${ }^{\mathrm{TM}}$ via an evaluation team. Therein, STEM-Up ${ }^{\mathrm{TM}}$ delivered a portfolio of services that included: in-class activities, Viva Technology Programs, science fairs, parent workshops, and teacher workshops and community events.

\section{Option Year 2}

In 2010-11 STEM-Up ${ }^{\mathrm{TM}}$ became more rooted in the community as GMiS increased the delivery of school-based activities, extended the number of grades served, enhanced the hands-on activities, designated Teacher Ambassadors, and increased the number of STEM professional development opportunities for teachers. The professional development offered educators opportunities to gain resources and learn interactive techniques to be used in the classroom. In 
addition, there was an increase in the number of near-peer role models from local colleges and universities and an expansion of the partnership with the Society of Military Engineers (SAME). The SAME partnership supported elementary school STEM activities efforts and goals. These indicators of institutionalization increased both the depth and scope of the Initiative.

\section{Option Year 3}

Today, STEM-Up ${ }^{\mathrm{TM}}$ serves 13 elementary schools, three middle schools, and four high schools. These 20 schools are under the direct supervision of LAUSD, Local District 5, and the Partnership for Los Angeles Schools (PLAS). The Initiative continues to move forward in supplying its menu of opportunities and honing its offering to the community. This year serves as the second year of offering the full range of programs and opportunities. As such, GMiS is collecting more comprehensive evaluation data on the various compoents of STEM-Up ${ }^{\mathrm{TM}}$.

STEM-Up ${ }^{\text {TM }}$ Components

The strength and uniqueness of STEM-Up ${ }^{\mathrm{TM}}$ is that it is a community-based program built on a framework to function in concert with neighborhood schools and the local school districts to supplement and expand on the formal and informal science and math curriculum. The initiative does not replace the work that the school is doing rather it complements work already taking place. Working with school administrators on an individual basis, STEM-Up ${ }^{\mathrm{TM}}$ supplements their established school plans in the promotion of STEM.

To that effect, STEM-Up ${ }^{\mathrm{TM}}$ developed a menu of interrelated opportunities (Table 2) that engage students, parents, teachers, administrators, local entrepreneurs and community-based organizations around STEM hands-on activities, role models, and career options. Schools are provided the same opportunities; implementation however, is based on customized choices and needs of the individual school site. STEM-Up ${ }^{\mathrm{TM}}$ efforts are unique to each campus to maximize participation and impact.

Table 2. Sample of STEM-Up TM Components

\begin{tabular}{|c|c|c|c|}
\hline Opportunity & $\begin{array}{c}\text { Elementary } \\
\left(3^{\text {rd }}-5^{\text {th }}\right)\end{array}$ & $\begin{array}{l}\text { Middle School } \\
\left(6^{\text {th }}-8^{\text {th }}\right)\end{array}$ & $\begin{array}{c}\text { High School } \\
\left(9^{\text {th }}-12^{\text {th }}\right)\end{array}$ \\
\hline STEM-Up ${ }^{\mathrm{TM}}$ Homework Agendas & $\mathrm{x}$ & $\mathrm{x}$ & $\mathrm{x}$ \\
\hline In-class Hands-on Activities & $\mathrm{x}$ & & \\
\hline Viva Technology ${ }^{\mathrm{TM}}$ & & $\mathrm{x}$ & $\mathrm{x}$ \\
\hline Science Fair Support & $\mathrm{x}$ & $\mathrm{x}$ & \\
\hline STEM Showdown $^{\mathrm{TM}}$ & & & $\mathrm{x}$ \\
\hline Teacher Workshops \& Teacher Ambassadors & $\mathrm{x}$ & $\mathrm{x}$ & $\mathrm{x}$ \\
\hline Parent Workshops & $\mathrm{x}$ & $\mathrm{x}$ & $\mathrm{x}$ \\
\hline Awareness Campaign Material Distribution & $\mathrm{x}$ & $\mathrm{x}$ & $\mathrm{X}$ \\
\hline
\end{tabular}




\begin{tabular}{llll} 
STEM Spirit Bulletin Boards & $\mathrm{x}$ & $\mathrm{X}$ & $\mathrm{X}$ \\
College \& Career Pathway Presentations & $\mathrm{x}$ & $\mathrm{x}$ \\
\hline
\end{tabular}

Following is a summative description of three of the component opportunities:

\section{STEM-Up ${ }^{T M}$ Homework Agendas}

Great Minds in STEM ${ }^{\mathrm{TM}}$ recognizes the importance of developing sound organizational skills early in a child's education. Not only are organization skills generally important, but this skill helps prevent low academic performance. Often times, students and parents are unaware of due dates for tests and projects, and are in a rush to complete the assignments, which may result in a low performance grade.

The STEM-Up ${ }^{\mathrm{TM}}$ Homework Agenda is a tool for students to note their academic due dates, sport and extracurricular activities, college application, testing and financial aid deadlines, community service opportunities, and family/personal events. Students are taught backward planning to schedule reminders and benchmarks of upcoming due dates. They learn how to make the planner part of their daily routine and how to design an effective color-code system to track their time management. In the second and third year of the Initiative (2009-2011) over 30,000 STEM-Up ${ }^{\mathrm{TM}}$ Homework Agendas were distributed to students.

\section{STEM-Up TM In-Class Hands-on Activities}

One of the opportunities afforded through STEM-UP ${ }^{\mathrm{TM}}$ are STEM hands-on activities for $4^{\text {th }}$ and $5^{\text {th }}$ grade students in our partner elementary schools. The National Science Education Standards, published by the National Research Council, espouses that science is an active process that not only requires "hands-on" but "minds-on learning." The scientific literacy of students must be such that they have the knowledge and understanding of scientific concepts and processes.

The STEM-Up ${ }^{\mathrm{TM}}$ in-class hands-on activities give students the ability to explore scientific concepts and processes, as well as provide students an awareness of STEM related careers. The activities are in-line with the California State Standards and are delivered during school hours to help supplement teacher lesson plans around STEM topics. In the second and third year of the Initiative, from Fall 2009 to Spring 2011, 256 in-class hands-on activities were delivered to $7,5004^{\text {th }}$ and $5^{\text {th }}$ grade students at 13 STEM-Up ${ }^{\text {TM }}$ elementary schools.

This spring 2012, STEM-Up ${ }^{\mathrm{TM}}$ is expanding the in-class hands-on activities these activities to select 3rd grade and $6^{\text {th }}$ grade classrooms. This expansion is representative of the demand for STEM that the Initiative has created within the community.

\section{Viva Technology ${ }^{T M}$}

Viva Technology $^{\mathrm{TM}}$ is GMiS' signature, national pre-college program that engages students in activities intended to stimulate interest in the application of technology and opens doors to academic achievement in math and science. Viva Technology ${ }^{\mathrm{TM}}$ is a three-part program that 
engages parents, teachers, and students. To date, 27 Viva Technology ${ }^{\mathrm{TM}}$ programs have been conducted for middle and high students in Boyle Heights.

This academic year, 2011-2012, Viva Technology ${ }^{\mathrm{TM}}$ is celebrating its $10^{\text {th }}$ Anniversary. Nationwide, the Program has reached over 70,000 students, parents, and teachers in 18 states. Through its three components that consists of a Parent Orientation, a Teacher Orientation and a Student Day. The Viva Technology ${ }^{\mathrm{TM}}$ Parent Orientation is a two-hour session that takes place the evening prior to the Viva Technology ${ }^{\mathrm{TM}}$ Student Day. The session explains to parents what their child will learn in the program; why encouraging interest in math and science will positively impact their child's future; and what career opportunities lay ahead for their child in science, engineering and technology. The Viva Technology ${ }^{\mathrm{TM}}$ Teacher Orientation features information and materials to acquaint teachers with the entire Viva Technology ${ }^{\mathrm{TM}}$ Program. GMiS provides them training and resources that they can apply in encouraging their students to enter into STEM fields. The orientation demonstrates donated hands-on project materials and adjoining handout and training materials for real STEM activities intended for classroom use.

The Viva Technology ${ }^{\mathrm{TM}}$ Student Day hosts approximately 100 middle school or high school students for an entire school day. Viva Technology ${ }^{\mathrm{TM}}$ challenges precollege students to apply their math and reasoning skills to real-world engineering problems. Local STEM college students serve as College Captains leading teams through the challenges posed to them throughout the day. Each team represents a STEM-field, and in this team-oriented environment, students role play as engineers and scientists. Through problem solving, students are introduced to the Engineering Design Process: 1) Identify a problem; 2) Brainstorm; 3) Design; 4) Build, Test, Evaluate, Redesign; and 5) Share Solutions. Participants also listen to keynote STEM professionals who talk about their own education pathway and STEM career.

\section{Evidence of Impact}

STEM-Up ${ }^{\mathrm{TM}}$ was not designed on traditional school reform strategies. The focus of the Initiative is not on individual gains in student achievement - i.e. standardized test scores, GPA, math or science proficiency, or promotions. The focus of the Initiative is transformative change through a value chain of STEM opportunities that relies on creating social network structures among and between students, parents, teachers and community stakeholders. To that effect, the evaluation strategies focused on the extent to which the attitudes, perceptions and behaviors of students, teachers, administrators and parents change in regards to the pursuit of math and science as a viable career pathway.

Table 3 presents a snapshot on how STEM-Up ${ }^{\text {TM }}$, as an informal science initiative, is impacting the Boyle Heights Community. Evidence shows an increase in Boyle Heights' students, parents, teachers, administrators, community leaders recognizing the importance and value of STEM careers and STEM-Up ${ }^{\mathrm{TM}}$. More than 80 percent of middle and high school students participating in STEM-Up ${ }^{\mathrm{TM}}$ activities indicate that they plan to attend college. Of the middle school and high school student participants, 100 percent indicate being positively influenced by the STEM-Up ${ }^{\text {TM }}$ College and Career Pathways resources and STEM career option presentations. Among teachers, there is an increase in the number whom credit the Summer STEM Workshops hosted at the CSULA College of Engineering Computer Science and Technology, for increasing their 
confidence and capacity to deliver STEM-related content in the classroom. School site administrators and teachers report that students are both beginning to understand the importance of science and math to their future careers and notice an increase in students' motivation to perform better in their match and science classes after participating in STEM-Up ${ }^{\mathrm{TM}}$ hands-on activities.

Table 3. Evidence of Impact

STEM-Up ${ }^{\mathrm{TM}}$ Objectives

Objective 1: Increase community

awareness of the value and

importance of STEM

Objective 2: Motivate students and families to prepare themselves for STEM careers

Objective 3: Build long-term community support for expanding STEM capacity

Objective 4: Increase the STEM content knowledge of K-12 STEM teachers and administrators

Objective 5: Expand career opportunities in STEM fields

Objective 6: Raise the achievement of students in STEM disciplines.

Objective 7: Increase the number of students entering and being accepted into higher education.
Evidence of Impact

Boyle Heights students, parents, teachers, administrators, business owners, and community leaders have come to recognize GMiS staff as "the STEM-Up people.”

$100 \%$ of students surveyed indicated that they had been positively influenced by STEM-Up’s College and Career Pathways presentations

STEM-Up ${ }^{\text {TM }}$ has solidified the framework of community support needed to sustain the initiative with two advisory boards - The Community Advisory Board and The Corporate and Government Advisory Board.

Teachers credit the Summer Institute hosted at the College of Engineering at CSU-LA, for increasing their confidence and capacity to deliver STEMrelated content in the classroom.

The STEM-Up ${ }^{\mathrm{TM}}$ Corporate and Government Advisory Board has begun to develop an action agenda to provide a menu of competitive after-school and summer activities, specifically for highly motivated, high-potential students.

Teachers report that students are beginning to understand the importance of science and math to their future careers and are more motivated to do well in these subjects after participating in STEM-Up ${ }^{\mathrm{TM}}$ hands-on activities.

More than $80 \%$ of middle and high school students participating in STEM-Up ${ }^{\mathrm{TM}}$ activities indicate that they plan to attend college.

As the Initiative prepares for its 5-year contractual evaluation, it has initiated a couple of additional assessment projects to evaluate the impact of specific opportunities. In 2011, as part of the fall distribution of the STEM-Up ${ }^{\mathrm{TM}}$ Student Agenda, elementary, middle, and high school 
students completed a pre-assessment regarding awareness, motivation, inspiration and skills in STEM. At the end of the academic year, a post-assessment will be distributed to these students. Over 12,000 pre-assessments were collected in fall 2011. As of the writing of this paper, data was still being inputted.

This spring 2012, GMiS has implemented a controlled study to measure the impact of STEMUp ${ }^{\mathrm{TM}}$ among $6^{\text {th }}$ grade students. In 2011-12, students entering $6^{\text {th }}$ grade from the STEM-Up ${ }^{\mathrm{TM}}$ feeder elementary schools, would have had the opportunity to participate in $4^{\text {th }}$ and $5^{\text {th }}$ grade STEM-Up ${ }^{\mathrm{TM}}$ in-class activities. In $6^{\text {th }}$ grade, students will have the opportunity to participate in the Viva Technology ${ }^{\mathrm{TM}}$ Program. Surveys will be administered to two groups of $6^{\text {th }}$ grade students participating in Viva Technology ${ }^{\mathrm{TM}}$. The first group will be students who participated in elementary school STEM-Up ${ }^{\mathrm{TM}}$ activities; the second group will include students who did not participate in STEM-Up ${ }^{\mathrm{TM}}$ activities at the elementary schools. The study design will look at the extent to which STEM-Up ${ }^{\mathrm{TM}}$ has motivated and changed attitudes and behaviors toward STEM.

GMiS is also creating STEM-Up ${ }^{\mathrm{TM}}$ High School Transition Survey and a Senior Exit Survey to assess the extent to which STEM-Up ${ }^{\mathrm{TM}}$ impacted attitudes, perceptions and behaviors toward STEM. The survey will also ask students about their high school curriculum plans, postsecondary plans, including acceptance in college, plans to attend college, and immediate and long-term career goals. This assessment will address STEM-Up ${ }^{\mathrm{TM}}$ Objective 7, not in direct regards to actual increases in numbers enrolling in higher education, but the potential likelihood of enrolling in STEM fields of study.

\section{Next Steps}

Moving forward, Great Minds in STEM ${ }^{\mathrm{TM}}$ is pursuing opportunities to enhance available offerings and build capacity to deliver the Initiative beyond the support from the U.S. Department of Defense within Boyle Heights and other underserved communities. These opportunities include increasing the presence of STEM-UpTM clubs, increasing the role of Teacher Ambassadors, formalizing Parent Ambassadors, and upgrading its online presence.

Increase and sustain STEM-Up ${ }^{T M}$ Clubs - The self-initiated STEM-Up ${ }^{\mathrm{TM}}$ Clubs gathered momentum in 2010-11. Teachers and students came together to coalesce the foundation laid by STEM-Up ${ }^{\mathrm{TM}}$ at their schools. These clubs represent a move to firmly create sustainability and identity of STEM-Up ${ }^{\mathrm{TM}}$ within the schools. GMiS intends to leverage this momentum and help other STEM-Up schools create STEM-Up ${ }^{\mathrm{TM}}$ Clubs. The intent is to create an informal social network that will sustain broadened participation among students as they prepare to enter college and become part of the STEM-Up ${ }^{\mathrm{TM}}$ Alumni.

STEM-Up ${ }^{T M}$ Teacher Ambassadors - Research continues to suggest the need for reinvigorating and re-tooling teachers with new pedagogies. STEM-Up ${ }^{\mathrm{TM}}$ intends to grow its current K-12 Educators' Institute into The K-12 Educators’ Academy of STEM Institutes, which will include three institutes. The Advanced Institute will host STEM teachers from the STEM-Up ${ }^{\mathrm{TM}}$ Initiative. The Intermediate Institute will host STEM teachers, who are new to the STEM-Up ${ }^{\text {TM }}$ Initiative. The Beginners Institute will host pre-service teachers, who have an interest in bringing STEM into their own classrooms upon entering the teaching workforce. Just like the 
STEM-Up Clubs, GMiS intents to create a professional network among educators that extends beyond the traditional classroom. STEM-Up ${ }^{\mathrm{TM}}$ values the critical agency that teachers posses as change agents for the Boyle Heights Community. Therein, GMiS recognizes the imperative to not only expand the breadth of STEM-Up ${ }^{\mathrm{TM}}$ Teacher Ambassadors, but also deepen their engagement.

Parents as STEM-Up ${ }^{T M}$ Parent Ambassadors - As a family-oriented community with multiple generations of students attending the various schools within Boyle Heights, parents are a key community resource in bringing the conversation of STEM to the dinner table and making STEM part of the family vernacular. Research continues to demonstrate a plethora of evidence regarding the positive impact of parental engagement and parental involvement on the college success of students, especially for Latinos. STEM-Up ${ }^{\mathrm{TM}}$ intends to create the Parent Ambassadors Empowered for STEM Success (PAESS). The PAESS will include a bilingual Parent STEM Academy for a cohort of parents over a 12-week period each spring. Parents will be individuals, who currently have students enrolled in one of the STEM-Up ${ }^{\mathrm{TM}}$ elementary schools. The goal of PAESS is to create a network of STEM-Up ${ }^{\mathrm{TM}}$ Parent Ambassadors informed with the tools and resources to sustain a college-going culture within Boyle Heights. STEM-Up ${ }^{\text {TM }}$ Parent Ambassadors will be invited to co-host the weekly sessions with local teachers, and design and deliver content that builds sustained parental engagement. This is the level of networks that GMiS intends to build for transformative change within Boyle Heights toward an increased and sustained affinity for STEM.

Modernize Online Presence - Today's youth are more engaged in online social networks, gaming, and communication then the previous generation. GMiS intends to upgrade the STEM$\mathrm{Up}^{\mathrm{TM}}$ website to keep pace with the interconnectivity of K-12 students. Social media outlets, Podcasts, webcasts and interactive STEM games are currently being developed for future deployment. Downloadable STEM education and career content, designed and developed by GMiS will be uploaded as classroom resources. Parents will be able to access a broader array of information in Spanish. The site will also be designed to enable various access points regardless of the speed or type of connectivity.

\section{Conclusion}

STEM-Up ${ }^{\mathrm{TM}}$ is causing transformative change in the Boyle Heights community. Through its value chain of STEM opportunities, the Initiative is engaging various sectors of the community toward a greater affinity for math and science. Now in its second year of full implementation, STEM-Up ${ }^{\text {TM }}$ is slowly becoming part of the household vernacular in order to transform Boyle Heights into a community that values science and math. The observed changes in motivation, aspiration, attitudes and behaviors toward an affinity for science and math, and the education and career opportunities afforded therein are becoming embedded more deeply to create a collegegoing, STEM-focused culture beyond the scope of STEM-Up ${ }^{\mathrm{TM}}$. Given its progressive investment in Boyle Heights, GMiS projects to take increased steps to solidify and continue to break new ground in other communities and the U.S. 


\section{References}

1 Langdon, D., McKittrick, G., Beede, D., Khan, B., \& Mark Doms, M. (2011). STEM: Good Jobs Now and for the Future. ESA 03-11. Washington DC: U.S. Department of Commerce.

2 Dohm, A., \& Shniper, L. (2007). Occupational employment projections to 2016. Monthly Labor Review. Washington, DC: U.S. Department of Labor, Bureau of Labor Statistics.

3 Bureau of Labor Statistics. (2007). Table 1: The 30 fastest growing occupations covered in the 2008-2009 Occupational Outlook Handbook. http://www.bls.gov/news.release/ooh.t01.htm.

4 U.S. Department of Education. (2010), Transforming American Education: Learning Powered by Technology, Washington, D.C.: Office of Educational Technology.

5 Santiago, D. \& Callan, P. (2010). Ensuring America's Future: Benchmarking Latino College Completion to Meet National Goals: 2010 to 2020. Washington DC: Excelencia in Education.

6 Ibid.

7 President's Council of Advisors on Science and Technology. (2012). Engage to Excel: Producing One Million Additional College Graduates with Degrees in Science, Technology, Engineering, and Mathematics. Washington DC: Executive Office of the President.

8 Milken Institute (2010). Restoring California's Promise. Santa Monica, CA: Milken Institute.

9 Shen, I.L., Wong, P., \& DeVol, R C. (2011). What Brain Drain? California Among the Best in U.S. at Retaining Skilled Workers. Santa Monica, CA: Milken Institute.

10 U.S. Department of Education (2011). Table 333: Bachelor's degrees conferred by degree-granting institutions, by field of study and state or jurisdiction: 2008-09. Digest of Education Statistics: 2010. Washington DC: National Center for Education Statistics.

11 Alliance for Science \& Technology Research in America - ASTRA. (2010). California R\&D 2010: Research and Engineering Investments for Economic Growth.

12 National Research Council. (2009). Rising Above the Gathering Storm: Energizing and Employing America for a Brighter Economic Future. Washington, DC: The National Academies Press.

13 National Research Council. (2010). Rising Above the Gathering Storm Revisited: Rapidly Approaching Category 5. Washington, DC: The National Academies Press.

14 National Research Council. (2011). Expanding Underrepresented Minority Participation: America's Science and Technology Talent at the Crossroads. Washington, DC: The National Academies Press.

15 National Science Board. (2010). Preparing the Next Generation of STEM Innovators: Identifying and Developing our Nation's Human Capitol. Washington DC.

16 See Number 14.

17 See Number 15.

18 National Science Foundation. (2011). Women, Minorities, and Persons with Disabilities in Science and Engineering: 2011. (NSF 11-309). Arlington, VA. National Science Foundation

19 Ibid.

20 Ibid.

21 Ibid.

22 de los Santos, A. G., Keller, G. D., Nettles, M. T., Payan, R., \& Magallan, R. J. (Eds.). (2006). Latino achievement in the sciences, technology, engineering, and mathematics [Special issue]. Journal of Hispanic Higher Education, 5, 3.

23 U.S. Department of Education. (2011). Winning the Future: Improving Education For The Latino Community. Washington DC: White House Initiative on Educational Excellence for Hispanics.

24 Ibid.

25 Pew Hispanic Center. (2010). Statistical Portrait of Hispanics in the United States, 2010. Washington DC: Pew Hispanic Center.

26 Zhe, J., Doverspike, D., Zhao, J., Lam, P., \& Menzemer, C. (2010). High school bridge program: A multidisciplinary STEM research program. Journal of STEM Education: Innovations and Research.

27 Stolle-McAllister, K., Sto Domingo, M. R., \& Carillo, A. (2011). The Meyerhoff Way: How the Meyerhoff Scholarship Program Helps Black Students Succeed in the Sciences. Journal of Science Education and Technology, 20: 5-16.

28 Chacon, P. \& Soto-Johnson, H. (2003). Encouraging Young Women to Stay in the Mathematics Pipeline: Mathematics Camps for Young Women. School Science and Mathematics, 103, 274-284. 
29 Russell, S. H. , Hancock, M. P., \& McCullough, J. (2007). benefits of undergraduate research experiences. Science 316, 548-549.

30 See Number 26.

31 National Action Council for Minorities in Engineering. (2008). Confronting the "New" American Dilemma. White Plains, NY: NACME. 